\title{
Implications of large-scale iron fertilization of the oceans
}

\author{
Idea: Howard Browman, Philip W. Boyd \\ Coordination: Philip W. Boyd
}

\section{CONTENTS}

Boyd PW

Introduction and synthesis

Denman KL

Climate change, ocean processes and ocean iron fertilization.....

Freestone D, Rayfuse R

Ocean iron fertilization and international law...........227-233

Orbach MK

Cultural context of ocean fertilization.

Huesemann MH

Ocean fertilization and other climate change

mitigation strategies: an overview

\section{Leinen $\mathbf{M}$}

Building relationships between scientists and

business in ocean iron fertilization....

\section{Karl DM, Letelier RM}

Nitrogen fixation-enhanced carbon sequestra-

tion in low nitrate, low chlorophyll seascapes. de Baar HJW, Gerringa LJA, Laan P, Timmermans KR Efficiency of carbon removal per added iron in ocean iron fertilization

\section{Law CS}

Predicting and monitoring the effects of largescale ocean iron fertilization on marine trace gas emissions

\section{Gnanadesikan A, Marinov I}

Export is not enough: nutrient cycling and carbon sequestration

Cullen JJ, Boyd PW

Predicting and verifying the intended and unintended consequences of large-scale ocean iron fertilization.

Watson AJ, Boyd PW, Turner SM, Jickells TD, Liss PS

Designing the next generation of ocean iron

fertilization experiments. $303-309$

\section{Introduction and synthesis}

\author{
Philip W. Boyd \\ NIWA Centre for Chemical and Physical Oceanography, Department of Chemistry, University of Otago, PO Box 56, \\ Dunedin, New Zealand
}

\begin{abstract}
A historical perspective of the scientific study of ocean iron fertilization (OIF) over the last $15 \mathrm{yr}$ prefaces a short synthesis of the multi-faceted issues raised by the 11 contributions to this Theme Section. These issues, which range from ethical to logistical, must be aired in discussions surrounding OIF and its commercial application as a potential climate mitigation tool. Two other issues, not considered in detail by the contributors, are also addressed: (1) the importance of the rate of change in atmospheric $\mathrm{CO}_{2}$ following sustained global OIF (other than model simulations, the only data presently available to assess this comes from the geological record, e.g. Vostok ice core record of dust supply and atmospheric $\mathrm{CO}_{2}$ ); and (2) the necessity of making realistic estimates of the cost of OIF (i.e. carbon sequestered per unit of iron added) to provide comparisons of the ratio of cost:environmental risk of OIF with other mitigation strategies.
\end{abstract}




\section{HISTORICAL PERSPECTIVE}

Ocean fertilization with nutrients is one of 2 potential methods of using the ocean to mitigate atmospheric $\mathrm{CO}_{2}$ concentrations that have received both wide media interest (Young 2007) and considerable scientific scrutiny (Boyd et al. 2007, Glibert et al. 2008). (The other method is deep ocean $\mathrm{CO}_{2}$ disposal; Parks 1999, Brewer et al. 1999, Tamburri et al. 2000). Initial discussion of the use of ocean iron fertilization (OIF) as a $\mathrm{CO}_{2}$ mitigation strategy resulted from John Martin's iron hypothesis (Martin 1990), in which he linked contemporary findings of the limitation of phytoplankton growth rates by iron supply (in 3 large oceanic regions) with variations in dust supply, anti-correlated with changes in atmospheric $\mathrm{CO}_{2}$, in the geological record. Prior to the publication of Martin's study, the release of a report on OIF by the US National Research Council Board on Biology resulted in a wave of publicity that included front-page headlines about OIF and climate mitigation in newspapers including the Washington Post.

The first comprehensive scientific evaluation of OIF as a mitigation strategy came at a meeting sponsored by the American Society of Limnology and Oceanography (ASLO) in San Marcos, California, in February 1991. More than 30 papers on aspects of OIF were published in a special issue of Limnology and Oceanography (Chisholm \& Morel 1991). Over 15 yr later, many of the issues raised and questions they posed remain: the motivation for OIF (a 'cheap, fast and easy' solution), the ethics of 'a massive intervention in the earth's biogeochemical cycle,' and how to devise 'philosophical and/or political frameworks for decision making about conducting OIF globally' (Chisholm \& Morel 1991, Preface). The outcome of this ASLO meeting was a consensus resolution of the participants that highlighted the scientific uncertainty of OIF as a mitigation strategy, which, even if implemented globally would probably have a short-term (years) and a relatively small effect that would merely delay the rise of atmospheric $\mathrm{CO}_{2}$ by several years, and thus be ineffectual in contributing to a long-term reduction on atmospheric $\mathrm{CO}_{2}$ levels. ASLO also advocated further research into OIF effects on the regulation of ocean productivity and its role in the carbon cycle, and advised against using OIF as a policy option for climate mitigation.

In the ensuing $15 \mathrm{yr}$ there has been a large body of research conducted, ranging from laboratory culture experiments (Sunda \& Huntsman 1995), to shipboard studies (Hutchins et al. 2001) and OIF modelling simulations (Aumont \& Bopp 2006). However, the most thorough investigation has come from eleven $10 \mathrm{~km}$ length-scale OIF experiments in subtropical, subpolar and polar high-nitrate, low-chlorophyll
(HNLC) waters between 1993 and 2005 (de Baar et al. 2005, Boyd et al. 2007). There have been OIF tests conducted by commercial companies (Markels \& Barber 2001, Schiermeier 2003). These OIF studies by commercial stakeholders were viewed as controversial and resulted in widespread debate within the scientific community (Chisholm et al. 2001, Johnson \& Karl 2002) that is still ongoing as evidenced during a symposium on OIF at Woods Hole Oceanographic Institution in October 2007 involving scientists, policy makers and commercial stakeholders (Powell 2008).

\section{AIMS OF THIS THEME SECTION}

Within this Theme Section there are commentaries and research articles by a wide range of academics, each of whom brings expertise on aspects of the many scientific, technical, legal, commercial, environmental and ethical issues that encompass OIF. It is hoped that their counterpoint and breadth of discussion will provide a valuable tool for research scientists policy makers, educators and students to both grasp the complexity of the issues involved, and to assist with attaining a clearer picture of the key issues and the way forward.

The Theme Section commences with Denman, who examines OIF within the context of the ocean carbon cycle and global climate (Denman 2008, this Theme Section). He does this by stepping through 4 central issues (from mitigation objectives to side-effects) related to OIF. This assessment is followed by commentaries from Freestone \& Rayfuse on legal and environmental considerations of OIF and how these considerations relate to existing legislation for the ocean (e.g. the Law of the Sea [LOSC]) and the environment (Kyoto Protocol) (Freestone \& Rayfuse 2008, this Theme Section), and from Orbach on the ethics of altering the ocean commons by using global-scale manipulations such as OIF (Orbach 2008, this Theme Section). Huesemann then puts OIF into the context of other mitigation schemes, such as geological carbon sequestration and renewable energy generation from biomass (Huesemann 2008, this Theme Section). Such schemes were discussed at a geoengineering symposium at Harvard University (Kintisch 2007). Huesemann's article leads on to a commentary by Leinen (of the company CLIMOS, www.climos. com), who describes how scientists and business can better align themselves to carry out OIF studies at scales larger than the $10 \mathrm{~km}$ length scale of the first-generation experiments (Leinen 2008, this Theme Section). Such studies are required to better understand the longer term and larger scale impacts of OIF (Buesseler et al. 2008).

The remainder of the Theme Section focuses on some key unresolved scientific questions. Karl \& Lete- 
lier explore whether fertilization-either via iron and/or phosphate enrichment or stimulation of the upwelling of nutrient-rich waters (Lovelock \& Rapley 2007) - of the oligotrophic low-latitude ocean will result in blooms of nitrogen fixers, ultimately resulting in the net transport of carbon to the deep sea (Karl \& Letelier 2008, this Theme Section). De Baar et al. discuss the efficiency of OIF at removing $\mathrm{CO}_{2}$ from the atmosphere and the range of factors that determine this efficiency (De Baar et al. 2008, this Theme Section). Law provides insights into how the concentrations of other biogenic gases in the upper ocean, which have potentially negative (i.e. nitrous oxide) or positive (dimethylsulphide) effects on radiative forcing and hence climate, might be altered during the proposed larger scale $(>10 \mathrm{~km}$ ) and longer (months) OIF studies (Law 2008, this Theme Section).

In the only modelling study in this Theme Section, Gnanadesikan \& Marinov present simulations of the longer-term (years to decades) biogeochemical trajectory (and the interplay with ocean circulation) and fate of a large-scale $\left(4^{\circ} \times 4^{\circ}\right)$ OIF study (Gnanadesikan \& Marinov 2008, this Theme Section). They conclude that the veracity of OIF as a mitigation strategy is more closely aligned to the fate of the nutrients taken up by the biota than to the export of carbon to depth. The 2 concluding papers deal with logistical and technical issues. Cullen \& Boyd comment on the difficulties posed by verification of the outcomes from OIF (Cullen \& Boyd 2008, this Theme Section) and Watson et al. provide an analysis of what will be required (from both modellers and observationalists) to devise, design and implement the second generation of OIF (at a $100 \mathrm{~km}$ length scale) (Watson et al. 2008, this Theme Section).

\section{OTHER ISSUES}

Despite the breadth of issues tackled and the wider range of views aired in this Theme Section, 2 important topics receive less attention than they merit: (1) the utility of the geological record in assessing the timescales of carbon sequestration resulting from global OIF, and (2) the financial cost of carbon sequestration during large-scale OIF studies.

\section{Geological records of the temporal relationship between OIF and climate}

In a recent policy statement on OIF, Buesseler et al. (2008) indicate that if widespread (i.e. global) OIF was to be viewed as a wedge to help stabilise atmospheric $\mathrm{CO}_{2}$ concentrations (Pacala \& Socolow 2004), the rate of change in atmospheric $\mathrm{CO}_{2}$ due to global OIF will be just as critical as its magnitude. Buesseler et al. (2008) reported an upper bound for sequestration of $0.5 \mathrm{Gt} \mathrm{C}$ $\mathrm{yr}^{-1}$, corresponding to a reduction of 0.24 ppmv atmospheric $\mathrm{CO}_{2} \mathrm{yr}^{-1}$ (Cullen \& Boyd 2008). However, this sequestration estimate was based on a modelling study of global OIF (Aumont \& Bopp 2006). Given the critical importance of estimating the rate of OIF-mediated C sequestration in order to assess whether it can be viewed as a climate stabilisation wedge, there is one dataset - from the geological past - that can be used to evaluate the predictions from models of global OIF.

The Vostok ice core record of dust and atmospheric $\mathrm{CO}_{2}$ concentrations across 4 glacial-interglacial cycles was the centrepiece of the iron hypothesis (Martin 1990) and led to OIF being considered as a potential climate mitigation tool (Keith \& Dowlatabadi 1992). Much of the subsequent debate on the Vostok record has focussed on (1) what mechanism(s) caused the 80 ppmv change in atmospheric $\mathrm{CO}_{2}$ concentrations and their relative contribution to this change (Watson et al. 2000, Toggweiler et al. 2006), and (2) the timing of changes in the dust flux relative to those in atmospheric $\mathrm{CO}_{2}$ (Watson et al. 2000). It has been suggested that up to $30 \%$ of the 80 ppmv atmospheric $\mathrm{CO}_{2}$ drawdown could be attributed to OIF (Sigman \& Boyle 2000) and modelling studies indicate that increased dust supply probably caused the initial decrease (i.e. up to 25 ppmv) in atmospheric $\mathrm{CO}_{2}$, and was then superseded by other causative mechanisms that drew down a further 55 ppmv (Watson et al. 2000). Thus, the magnitude of atmospheric $\mathrm{CO}_{2}$ drawdown due to global OIF has an upper bound of ca. 25 ppmv.

The temperature- $\mathrm{CO}_{2}$ relationship from Vostok has been interpreted as a marked alteration of global climate to which OIF made a significant contribution; therefore the magnitude of this signal has been cited widely by observationalists (Martin 1990, de Baar et al. 2005), modellers (Aumont \& Bopp 2006) and commercial ventures (e.g. www.climos.com) interested in the OIF debate. However, there has been little emphasis to date on the equal importance of the rate of change in atmospheric $\mathrm{CO}_{2}$ due to global OIF (Boyd et al. 2007).

Given the difficulties in planning and conducting an OIF event at the $100 \mathrm{~km}$ length scale (Watson et al. 2008), the Vostok record is a valuable resource that provides the most robust data available for the likely outcome from a sustained (i.e. millennia) global OIF event (termed here Vostok OIF), and thus gives a lowcost snapshot (relative to the outlay of doing a large scale OIF event, Watson et al. 2008) of the biogeochemical and climatic signature of such a global OIF event. Examination of the highest resolution (<500 yr) data of the Vostok record (Petit et al. 1999) reveals a ca. 20 ppmv drawdown in atmospheric $\mathrm{CO}_{2}$ concentrations over roughly 5000 to 10000 yr (Fig. 1). This yields 

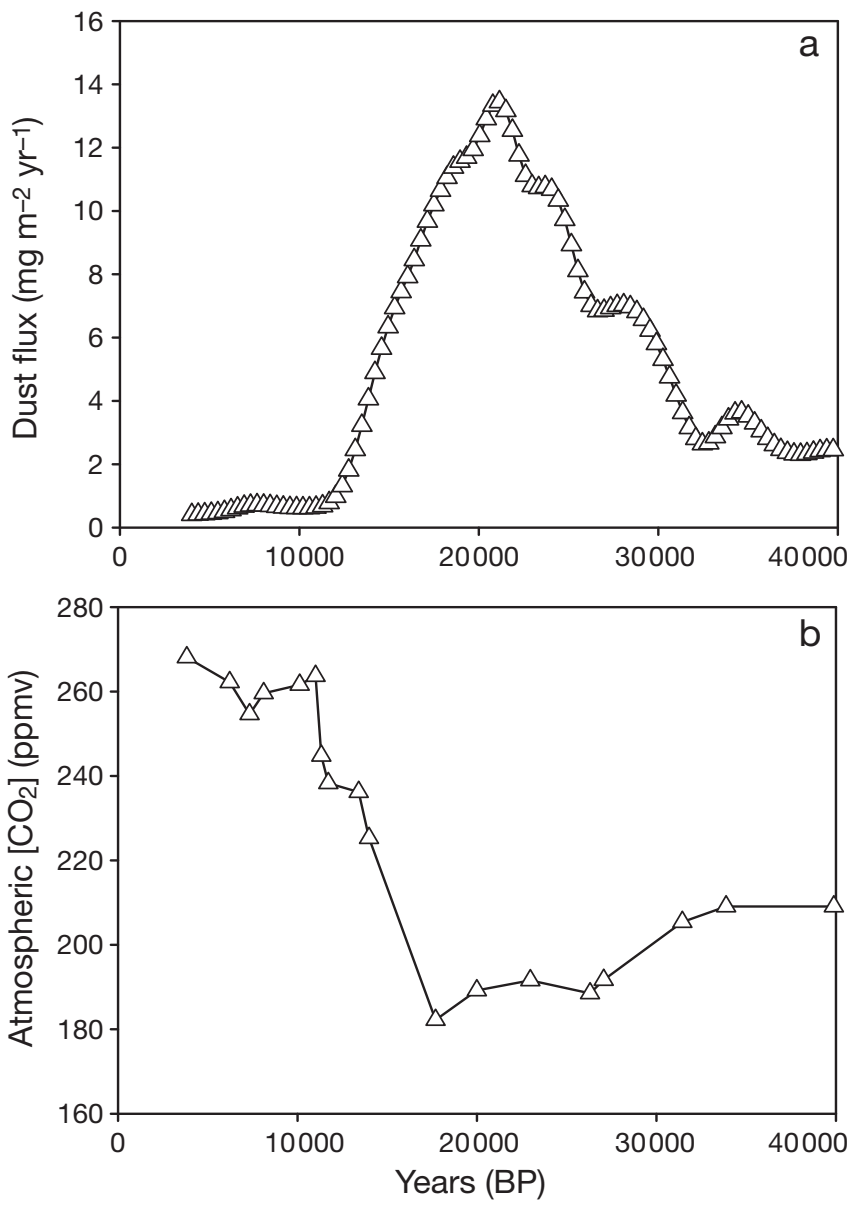

Fig. 1. High-resolution plots of the (a) dust flux and (b) atmospheric $\mathrm{CO}_{2}$ concentrations from the Vostok ice core record for the most recent glacial termination (i.e. the highest resolution data in the record were available for this period; Petit et al. 1999). The plots clearly indicate the 5000-10 000 yr timescale for decreases in atmospheric $\mathrm{CO}_{2}$ due to significant increases in the dust flux. The asymmetry in the atmospheric $\mathrm{CO}_{2}$ record, relative to that for dust, is due to ocean iron fertilization (OIF) being only one of the mechanisms responsible for the observed changes in atmospheric $\mathrm{CO}_{2}$; see modelling simulations by Watson et al. (2000), their Fig. 2b. Note, alternative hypotheses for the changes in the atmospheric $\mathrm{CO}_{2}$ records have been proposed (e.g. intensity of upwelling, Toggweiler et al. 2006)

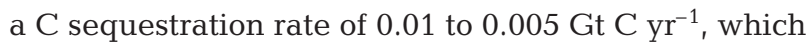
is significantly less than that estimated from modelling studies of global OIF (Aumont \& Bopp 2006) and would therefore not represent a 'Pacala \& Socolow' climate stabilization wedge (Pacala \& Socolow 2004). Hence, a better understanding of the underlying reasons for the disparity between the modelling study (Aumont \& Bopp 2006) and the Vostok record (Fig. 1) is urgently required.

The outcome of the Vostok OIF is the integral of a wide range of oceanic processes over millennia that may be altered directly (primary and export produc- tion) or indirectly (biogenic gas production, foodweb structure) due to OIF and about which little is known on scales $>1000 \mathrm{~km}^{2}$ and $>1$ mo (Boyd et al. 2007). The impact of the Vostok OIF is reported to be greater in the Southern Ocean than in low latitude regions (Winckler et al. 2008); nonetheless, it does represent a global OIF event where dust supply increased worldwide - albeit by different magnitudes in each HNLC region (Winckler et al. 2008).

In models such as that of Aumont \& Bopp (2006) (see also Table 1 in Denman 2008), there are marked differences in how OIF is parameterized relative to what is evident from the Vostok record, such as dissolved iron being maintained at $2 \mathrm{nM}$ following an instantaneous increase at onset of the model run (cf. our Fig. 1). This and other factors prescribed in the model, such as the relatively high efficiency of carbon sequestration may in part explain the up to 100 -fold difference in the $\mathrm{C}$ sequestration rate between the simulations and Vostok. An additional distinction between Vostok and the Aumont \& Bopp (2006) model is that the latter is run under elevated atmospheric $\mathrm{CO}_{2}$ concentrations (due to climate change). A global OIF simulation by Aumont \& Bopp (2006) with no increase in atmospheric $\mathrm{CO}_{2}$ (i.e. comparable to the geological past) resulted in a $<10$ ppmv $\mathrm{CO}_{2}$ drawdown, but note this occurs within $100 \mathrm{yr}$ and so is still much more rapid than reported for Vostok. To determine whether global OIF could be a stabilization wedge, the reasons for the 100-fold difference in the rates of iron-mediated $\mathrm{C}$ sequestration between models and geological records require better resolution of the timescales and modes of control of global OIF.

\section{Evaluating the cost of sequestering carbon via OIF}

The principal attraction of using OIF as a mitigation strategy is the notion that it is a 'cheap, fast and easy' solution to climate change. This notion has been propagated through the popular press since the early 1990s and was discussed in Chisholm \& Morel (1991). It has been proposed that OIF could be carried out at low cost relative to other mitigation strategies (Keith et al. 2005, Huesemann 2008); this was based on \$US 2 US ton $^{-1} \mathrm{C}$ ( 1 US ton $=0.9072 \mathrm{t}$ ) sequestered (Markels \& Barber 2001). Other estimates of \$US 5 US ton ${ }^{-1} \mathrm{C}$ sequestered are reported online (www.en.wikipedia.org/wiki/Iron_ fertilization). The calculations of Markels (see http:// www.patentstorm.us/patents/6440367.html) appear to be based on several assumptions: (1) that 'each US ton of iron dumped could pull 30000 US tons of carbon from the atmosphere' (i.e. an Fe:C molar ratio of $\left.7.27 \times 10^{-6}\right)$ (http://www.wired.com/wired/archive/8.11/ ecohacking_pr.html); and (2) that $53 \%$ of the iron- 


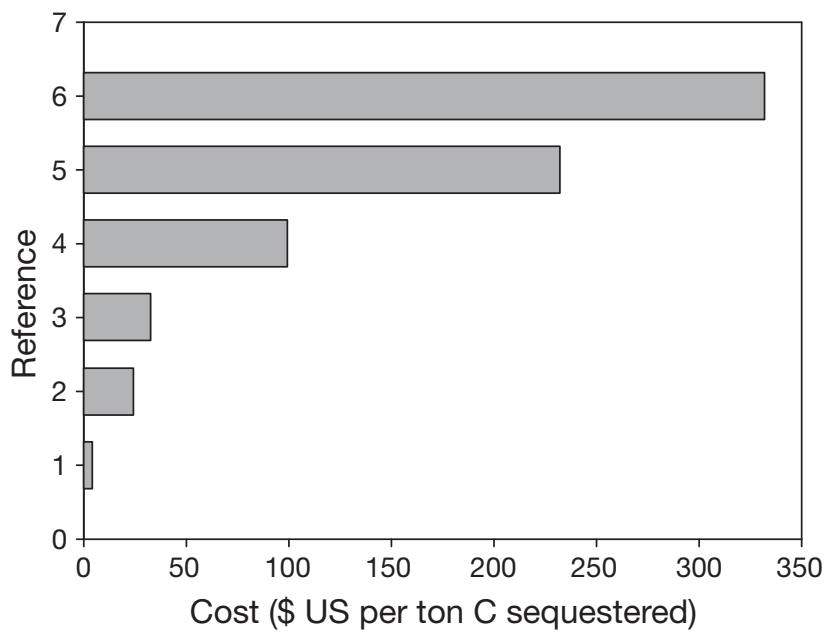

Fig. 2. Revised estimates of the cost of $\mathrm{C}$ sequestration by ocean iron fertilization (OIF). The estimates are based on the range of Fe:C molar ratios reported for mesoscale OIF studies and from naturally occurring blooms. These ratios are converted to a cost by simply scaling them using the Markels' Fe:C ratio of $1.37 \times 10^{-5}$ as equivalent to $\$$ US $2 \mathrm{US} \mathrm{ton}^{-1} \mathrm{C}$ sequestered. Reference 1: Markels' original estimate (http:// www.wired.com/wired/archive/8.11/ecohacking_pr.html); 2: Fe:C from Southern Ocean phytoplankton (Twining et al. 2004); 3: mixed layer particulate Fe:C from the Subarctic Ecosystem Response to Iron Enrichment Study (SERIES) OIF (Boyd et al. 2004); 4: Fe:C in sinking particles from the North Atlantic Bloom Experiment (Martin et al. 1993); 5 and 6: Fe:C in sinking particles, 5: exiting the mixed layer, and 6: sinking through the permanent pycnocline (120 m depth) during the SERIES OIF, respectively (Boyd et al. 2004). These Fe:C ratios are summarized in Boyd et al. (2007), their Fig. 3. Note these estimates do not include other potential costs, such as fisheries loss levy that are listed in the main text. 1 US ton $=0.9072 \mathrm{t}$

mediated increases in algal carbon are sequestered, based on the study of Hansell et al. (1997) in the equatorial Pacific (P. Lam \& S. W. Chisholm unpubl. data) ${ }^{\mathbf{1}}$. Taken together, this information suggests that each US ton of iron dumped could sequester 15900 US tons of carbon (i.e. an Fe:C molar ratio of $1.37 \times 10^{-5}$ ). Evidence from a mesoscale OIF event where the fate of the iron-mediated increase in algal carbon was measured directly (Boyd et al. 2004) and from natural open ocean blooms (Martin et al. 1993, de Baar et al. 2008) reveal that the $\mathrm{C}$ sequestration efficiency assumed by Markels is a significant overestimate; therefore the cost of sequestering carbon using OIF has so far been underestimated (Fig. 2).

Furthermore, the revised cost of $\mathrm{C}$ sequestration must also take into account other factors not included in the original estimate by Markels, including any deleterious downstream effects of OIF on the produc-

\footnotetext{
1 Iron fertilization of the oceans: reconciling commercial claims with published models. Unpublished white paper (2002). Available from S. W. Chisholm at: chisholm@mit.edu
}

tivity of commercial fisheries, where a fisheries loss levy could be up to \$US 150 US ton ${ }^{-1} \mathrm{C}$ sequestered (Gnanadesikan et al. 2003). From discussion of how $100 \mathrm{~km}$ length scale second generation OIF studies will be conducted (Watson et al. 2008) it is clear that the requisite OIF delivery systems (multiple vessels or aircraft), monitoring (remote-sensing), research and development (modelling), and verification (employment of independent evaluators) will also have to be included in such a cost estimate. These costs, when applied to a $100 \mathrm{~km}$ length-scale OIF event will probably not scale linearly but increase as a step function (Watson et al. 2008). There are also potentially hidden costs depending on the eventual outcome of OIF, including deduction of $\mathrm{C}$ offsets due to unanticipated side effects, such as greenhouse gas production (Law 2008). Although uncertainties remain, revised estimates - based simply on scaling Markel's original cost estimate to the $\mathrm{C}$ sequestration or export measured during first-generation OIF studies, such as SERIES (NE Pacific), indicate that the cost of $\mathrm{C}$ sequestered using OIF is between \$US 30 and \$US $300 \mathrm{t}^{-1}$ (Fig. 2).

This more realistic evaluation of the cost of the carbon sequestered using OIF suggests that the initial attraction - the estimated low cost of this approach is not valid. The revised estimate of the cost of OIF requires a reappraisal of the ratio of cost:environmental risk relative to other mitigation strategies. For OIF the degree of risk is reported as medium (Keith et al. 2005, Huesemann 2008), due to issues such as the possibility of unintended environmental side effects and difficulties in verification. Thus, OIF can be classified as a medium-risk, medium-cost mitigation strategy that may have similar costs to other, lower-risk mitigation strategies (for example, biomass with carbon capture, which Keith et al. 2005 estimated as costing SUS $300 \mathrm{t}^{-1} \mathrm{C}$ ).

Acknowledgements. This Theme Section owes much to the vision of Dr. H. Browman. We acknowledge the availability of the online datasets from Petit et al. (1999) for the Vostok ice core records of depth, ice age, gas age, and $\mathrm{CO}_{2}$ concentration to 414000 yr BP (IGBP PAGES/World Data Center for Paleoclimatology Data Contribution Series \#2001-076). We thank H. H. Janssen and M. Seaman at MEPS, and all of the contributing authors and manuscript reviewers.

\section{LITERATURE CITED}

Aumont O, Bopp L (2006) Globalizing results from ocean in situ iron fertilization studies. Global Biogeochem Cycles 20:GB2017

Boyd PW, Law CS, Wong CS, Nojiri Y and others (2004) The decline and fate of an iron-induced subarctic phytoplankton bloom. Nature 428:549-553

Boyd PW, Jickells T, Law CS, Blain S and others (2007) Mesoscale iron enrichment experiments 1993-2005: Synthesis and future directions. Science 315:612-617 
Brewer P, Friederich G, Peltzer ET, Orr FM Jr (1999) Direct experiments on the ocean disposal of fossil fuel $\mathrm{CO}_{2}$. Science 284:943-945

Buesseler KO, Doney SC, Karl DM, Boyd PW and others (2008) Ocean iron fertilization - moving forward in a sea of uncertainty. Science 319:162

Chisholm SW, Morel FMM (1991) What controls phytoplankton production in nutrient-rich areas of the open sea? Limnol Oceanogr 36 Preface

Chisholm SW, Falkowski PG, Cullen JJ (2001) Dis-crediting ocean fertilization. Science 294:309-310

> Cullen JJ, Boyd PW (2008) Predicting and verifying the intended and unintended consequences of large-scale ocean iron fertilization. Mar Ecol Prog Ser 364:295-301

de Baar HJW, Boyd PW, Coale KH, Landry MR and others (2005) Synthesis of iron fertilization experiments: from the Iron Age in the Age of Enlightenment. J Geophys Res 110: C09S16

de Baar HJW, Gerringa L, Laan P, Timmermans K (2008) Efficiency of carbon removal per added iron in ocean iron fertilization. Mar Ecol Prog Ser 364:269-282

$>$ Denman K (2008) Climate change, ocean processes, and iron fertilization. Mar Ecol Prog Ser 364:219-225

> Freestone D, Rayfuse R (2008) Ocean iron fertilization and international law. Mar Ecol Prog Ser 364:227-233

Glibert PM, Azanza R, Burford M, Furuya K and others (2008) Ocean urea fertilization for carbon credits poses high ecological risks. Mar Pollut Bull 56(6):1049-1056

> Gnanadesikan A, Marinov I (2008) Export is not enough: nutrient cycling and carbon sequestration. Mar Ecol Prog Ser 364:289-294

> Gnanadesikan A, Sarmiento JL, Slater RD (2003) Effects of patchy ocean fertilization on atmospheric carbon dioxide and biological production. Global Biogeochem Cycles 17: 1050

> Hansell DA, Bates NR, Carlson CA (1997) Predominance of vertical loss of carbon from surface waters of the equatorial Pacific Ocean. Nature 386:59-61

Huesemann MH (2008) Ocean fertilization and other climate change mitigation strategies: an overview. Mar Ecol Prog Ser 364:243-250

Hutchins D, Sedwick P, DiTullio G, Boyd P, Quéguiner B, Griffiths F, Crossley C (2001) Control of phytoplankton growth by iron and silicic acid availability in the subantarctic Southern Ocean: Experimental results from the SAZ Project. J Geophys Res 106:31559-31572

> Johnson KS, Karl DM (2002) Is ocean fertilization credible and creditable? Science 296:467-468

Karl DM, Letelier RM (2008) Nitrogen fixation-enhanced carbon sequestration in low nitrate, low chlorophyll seascapes. Mar Ecol Prog Ser 364:257-268

Keith DW, Dowlatabadi H (1992) A serious look at geoengineering. Eos Trans AGU 73:289-293

Keith DW, Ha-Duong M, Stolaroff JK (2005) Climate strategy with $\mathrm{CO}_{2}$ capture from the air. Clim Change 74:17-45

Kintisch E (2007) Should we study geoengineering? A Science magazine panel discussion. Science 318:1054-1055

Law CS (2008) Predicting and monitoring the effects of large- scale ocean iron fertilization on marine trace gas emissions. Mar Ecol Prog Ser 364:283-288

Leinen M (2008) Building relationships between scientists and business in ocean iron fertilization. Mar Ecol Prog Ser 364:251-256

> Lovelock JE, Rapley CG (2007) Ocean pipes could help the Earth to cure itself. Nature 449:403

Markels M Jr, Barber RT (2001) Sequestration of carbon dioxide by ocean fertilization. Paper presented at the 1st Nat Conf on Carbon Sequestration, Natl Energy Technol Lab, Washington, DC, 14-17 May, 2001

Martin JH (1990) Glacial-interglacial $\mathrm{CO}_{2}$ change: the iron hypothesis. Paleoceanography 5:2-14

Martin JH, Gordon RM, Hunter CN, Tanner SJ (1993) Iron, primary production and carbon-nitrogen flux studies during the JGOFS North Atlantic Bloom Experiment. DeepSea Res II 40:115-1 34

> Orbach MK (2008) Cultural context of ocean fertilization. Mar Ecol Prog Ser 364:235-242

> Pacala S, Socolow R (2004) Stabilization wedges: solving the climate problem for the next 50 years with current technologies. Science 305:968-972

> Parks N (1999) Into the abyss: consigning carbon to the deep could slow climate change. New Scientist 162:14

> Petit JR, Jouzel J, Raynaud D, Barkov NI and others (1999) Climate and atmospheric history of the past 420000 years from the Vostok ice core, Antarctica. Nature 399: $429-436$

Powell H (2008) Should we fertilize the ocean to reduce greenhouse gases? Oceanus 46:1-27

Schiermeier Q (2003) The oresman. Nature 421:109-110

Sigman DM, Boyle EA (2000) Glacial/interglacial variations in atmospheric carbon dioxide. Nature 407:859-869

Sunda WG, Huntsman SA (1995) Iron uptake and growth limitation in oceanic and coastal phytoplankton. Mar Chem 50: $189-206$

Tamburri MN, Peltzer ET, Friederich GE, Aya I, Yamane K, Brewer PG (2000) A field study of the effects of $\mathrm{CO}_{2}$ ocean disposal on mobile deep-sea animals. Mar Chem 72: 95-101

> Toggweiler JR, Russell JL, Carson SR (2006) Midlatitude westerlies, atmospheric $\mathrm{CO}_{2}$, and climate change during the ice ages. Paleoceanography 21:PA2005

Twining BS, Baines SB, Fisher NS, Landry MR (2004) Cellular iron contents of plankton during the Southern Ocean Iron Experiment (SOFeX). Deep-Sea Res II 51:1827-1850

Watson AJ, Bakker DCE, Boyd PW, Ridgwell AJ, Law CS (2000) Effect of iron supply on Southern Ocean $\mathrm{CO}_{2}$ uptake and implications for glacial atmospheric $\mathrm{CO}_{2}$. Nature 407:730-733

Watson AJ, Boyd PW, Turner SM, Jickells TD, Liss PS (2008) Designing the next generation of ocean iron fertilization experiments. Mar Ecol Prog Ser 364:303-309

Winckler G, Anderson RF, Fleisher MQ, McGee D, Mahowald $\mathrm{N}$ (2008) Covariant glacial-interglacial dust fluxes in the equatorial Pacific and Antarctica. Science 320:93-96

> Young E (2007) Can 'fertilizing' the ocean combat climate change? New Scientist 195:42-45

Proofs received from author(s): July 2, 2008 